\title{
MECHANICAL, MICROSTRUCTURE AND WEAR BEHAVIOUR OF LM25/SIC/MICA METAL MATRIX COMPOSITE FABRICATED BY SQUEEZE CASTING TECHNIQUE
}

UDC: $539.4 .014: 669.715$

Orginal scientific paper

https://doi.org/10.18485/aeletters.2019.4.2.5

\author{
L. Natrayan*1, M. Senthil Kumar ${ }^{1}$ \\ ${ }^{1}$ School of mechanical and building sciences, VIT Chennai, Tamilnadu, India
}

\begin{abstract}
:
Metal matrix composite (MMC) has a unique class of light weight advanced engineered materials which are developed to give high strength, improved hardness, tensile strength, good elongation and good resistance to wear and tear hence increases the durability. It has good machinability properties, so that lightweight materials can replace the heavy materials like cast iron in aerospace and automobile industry. The aim of this research to study the mechanical and microstructure properties of LM25 reinforced with $\mathrm{SiC}$ particles and coated with mica fabricated by squeeze casting technique. Wear loss and mechanical properties such as hardness, tensile strength, elongation and yield strength wear studied. Microstructure with EDS studied using scanning electron microscope. Results show that with increasing the percentage of mica along with $10 \%$ SiC the MMC properties get enhanced.
\end{abstract}

ARTICLE HISTORY

Received: 16.04.2019.

Accepted: 11.06.2019.

Available: 30.06.2019.

\section{KEYWORDS}

Silicon carbide, Mica, Squeeze casting, hardness, yield

strength, SEM, tensile strength

\section{INTRODUCTION}

Composites development has been carried out since many years, these combinations to improve the base metal qualities began in the 1950s. To improve the properties of MMCs researchers tried numerous combinations of ceramic whiskers as reinforcements in 1960s which resulted in aerospace applications. The automobile industries started to develop these MMCs in 1970s because the conventional monolithic materials have limitations to achieve good combination of strength, stiffness, density and toughness [1]. When a metal is reinforced with another material, it forms metal matrix composite (MMC), to improve the properties of MMCs, two or more materials were added to the matrix such as to give birth to hybrid metal matrix composites (HMMC). These composites have evolved through years to meet the modern day engineered lightweight materials which can give good strength, resistance to wear and tear [2]. These lightweight materials increasing fuel efficiency in automobiles [3]. Good combinations of reinforcements along with matrix give various properties like mechanical, electrical and chemical properties. Continuous, discontinuous, short, whiskers can be used as reinforcements with the MMCs to get desired properties to meet the growing technology. Comparison to the other types of reinforced MMCs, particulate reinforced MMCs have better strength and high wear resistance are achieved [4]. Commonly used ceramic reinforcement is SiC, $\mathrm{Al}_{2} \mathrm{O}_{3}, \mathrm{~B} 4 \mathrm{C}, \mathrm{ZrO}_{2}$, etc. These composites also have improved hardness and thermal shock resistance [5]. LM25 is aluminium casting alloy (Al-Si7Mg), a grade of alloy which conforms to British standard 1490 LM25. The achievement of the specified minimum tensile properties of LM25 is dependent on maintaining the optimum magnesium content [6]. Therefore care must be taken during melting and degassing to avoid loss of magnesium by oxidation resulting from overheating or by excessive chlorination. The tensile properties of 
this grade of aluminium alloy at elevated temperatures are influenced by the condition (heat-treatment) of the castings and the duration at the elevated temperatures [7]. The heat treated LM25 alloy has fairly good machining properties, but tools need to be of high speed steel and must be kept sharp. A moderately high rate of tool wear can be expected during machining [8]. LM25 is highly resistant to corrosive attack by sea water and high marine atmospheres. The properties of silicon carbide are low density, high strength, low thermal expansion, high hardness, excellent thermal shock resistance and high elastic modulus [9]. The nearly perfect cleavage is the most prominent characteristics of mica, which can be explained by the hexagonal sheet-like arrangement of its atoms. The mica sheets are chemically inert, dielectric, elastic, flexible, lightweight, insulating, etc. which brings in a wide range of usage of mica commercially [10]. Stir casting method to incorporate $\mathrm{SiC}$ and mica into Al356 alloy were studied $[11,12]$, its founded that better strength and hardness are achieved with $\mathrm{Al} / 10 \mathrm{SiC}-3$ mica composites and with increase in mass fraction of mica improves the wear loss of the composites. Aluminium alloy (LM25) reinforced with SiC/E-glass and red mud by stir casting method. Results shows addition of reinforcement materials improves tensile strength, impact strength and reduces the percentage elongation, but addition of E-glass minimizes the hardness [13]. Very few authors reported mechanical properties of LM25 reinforced with $\mathrm{SiC}$ using stir casting method, No one reported on squeeze casting technique. In this research to studied the mechanical and wear properties of LM25 reinforced $\mathrm{SiC}$ particles and coated with mica fabricated by squeeze casting technique.

Table 1. Composition of LM25 Alloy

\begin{tabular}{|c|c|c|c|c|c|c|c|c|c|c|}
\hline $\mathrm{Cu}$ & $\mathrm{Mg}$ & $\mathrm{Si}$ & $\mathrm{Fe}$ & $\mathrm{Mn}$ & $\mathrm{Ni}$ & $\mathrm{Zn}$ & $\mathrm{Pb}$ & $\mathrm{Sn}$ & $\mathrm{Ti}$ & $\mathrm{Al}$ \\
\hline $0.1 \%$ & $0.20-0.60 \%$ & $6.5-7.5 \%$ & $0.5 \%$ & $0.3 \%$ & $0.1 \%$ & $0.1 \%$ & $0.1 \%$ & $0.05 \%$ & $0.2 \%$ & remainder \\
\hline
\end{tabular}

\section{EXPERIMENTAL WORK}

\subsection{Selection of Materials and Sample preparation}

LM25 was used as a matrix material and chemical composition of LM25 is presented in Table 1. As reinforcing materials, silicon carbide particles of size $10 \mu \mathrm{m}$ and mica with average size $15 \mu \mathrm{m}$ were used. Chemical compositions of mica are stated in Table 2.

The composition of matrix and reinforcements selected is shown in Table 3. Samples of the composites were fabricated with $0,3,6 \%$ mica respectively. These compositions of mica were used with $10 \%$ silicon carbide particles in each sample.

Table 2. Composition of Mica (\%)

\begin{tabular}{|c|c|c|c|c|c|c|c|}
\hline $\mathrm{SiO}_{2}$ & $\mathrm{Al}_{2} \mathrm{O}_{3}$ & $\mathrm{~K}_{2} \mathrm{O}$ & $\mathrm{Fe}_{2} \mathrm{O}_{3}$ & $\mathrm{Na}_{2} \mathrm{O}$ & $\mathrm{TiO}_{2}$ & $\mathrm{CaO}$ & $\mathrm{MgO}$ \\
\hline 45.57 & 33.10 & 9.87 & 2.48 & 0.62 & traces & 0.21 & 0.38 \\
\hline
\end{tabular}

Al the three samples of the compositions were fabricated using squeeze casting method. The squeeze casting route was employed to make sure that the reinforcements were uniformly distributed with less porosity [14].
Table 3. Sample preparation

\begin{tabular}{|c|c|c|c|}
\hline & LM 25 & SiC & Mica \\
\hline Sample 1 & 990 & 10 & 0 \\
\hline Sample 2 & 987 & 10 & 3 \\
\hline Sample 3 & 985 & 10 & 5 \\
\hline
\end{tabular}

The LM25 bar was cut into the required dimensions and amount for fabrication of the three samples showed in Table 3. Mica was procured from Mica Fabrication Export Pvt.Ltd., Chennai for the purpose of this study.

\subsection{Sample fabrication}

Fabrication started by first melting the LM25 alloy in an electric furnace with $750^{\circ} \mathrm{C}$. SiC and mica was preheated together to a temperature about $550 \circ \mathrm{C}$. The preheated reinforcement particles were added to the molten metal at about $750 \circ \mathrm{C}$ and were continuously stirred for about 8 minutes at $600 \mathrm{rpm}$ [15]. The squeeze casting setup is shown in Fig.1. This melt was released to the pathway to squeeze casting setup. Squeeze casting process parameters such as squeeze pressure $100 \mathrm{Mpa}$, pouring time $10 \mathrm{sec}$, and pressure holding time $15 \mathrm{sec}$ has maintained [6]. Molten metal poured to the squeeze casting die through pathway to get the desired shape. 


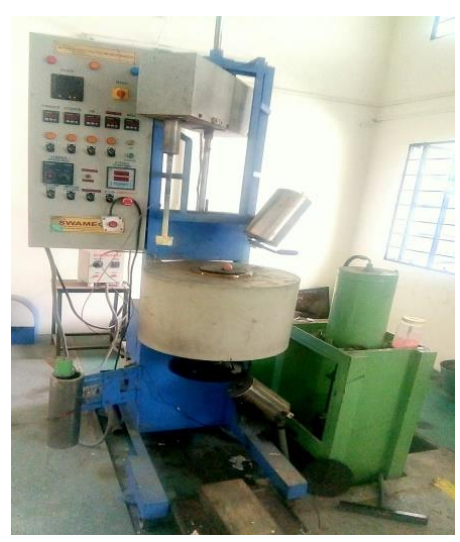

Fig.1. Squeeze casting setup

\subsection{Characterization}

Fabricated samples were machined as ASTM standard for taking mechanical and wear tests. For microstructure tests the samples were prepared by first rubbing them with emery paper of grade upto 1200 grit size which was followed by polishing the surface of the sample using Keller's reagent on a grinding machine using velvet cloth. These samples were then examined with a scanning electron microscope.

The tensile properties of the samples were carried out using an electric tensile testing machine at room temperature based on ASTM E8 standard. The cast samples were machined for testing purpose using lathe to get the required dimensions. Fig. 2 shows fabricated sample as per ASTM D3039 [16].

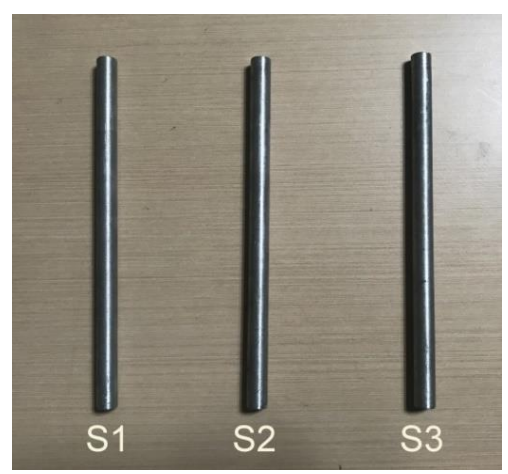

Fig.2. Tensile test samples

Hardness test of the samples were carried out using Rockwell's hardness testing machine to find out the effect of mica composition in the samples at load of $100 \mathrm{kgf}$ and dwell time of 10 seconds. Fig. 3 shows the hardness HMMC samples. The chemical composition of the different phases in the third sample with $5 \%$ mica was investigated using energy dispersed X-Ray (EDAX) detector.

On Fig.4. is shown wear test samples.

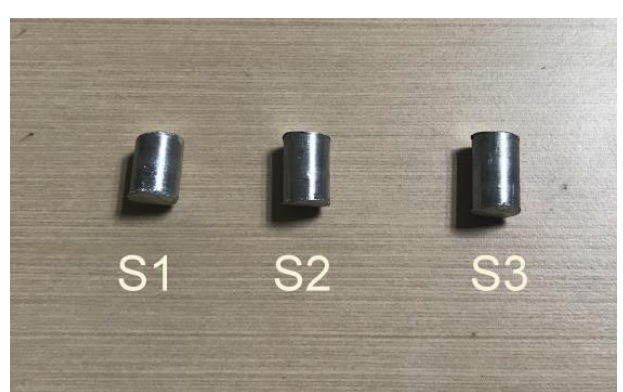

Fig.3. Hardness test samples

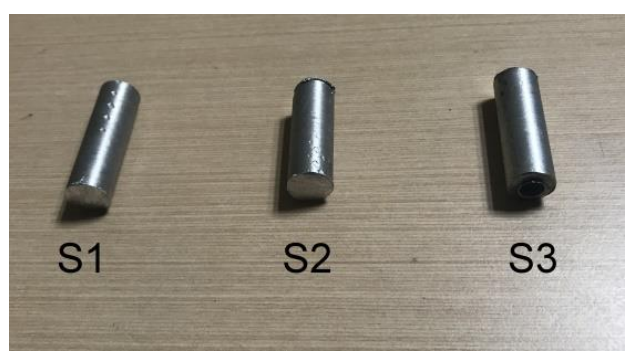

Fig.4. Wear test samples

\section{RESULTS AND DISCUSSION}

\subsection{Hardness}

Rockwell's hardness test results are shown in Fig.5. The hardness value of sample 1 (LM25/10SiC/Omica) has the least value and sample 3 (LM25/10SiC/5mica) have the highest hardness value compare then LM25 alloy. This shows that with the increase in amount of mica the hardness of the composite increases.

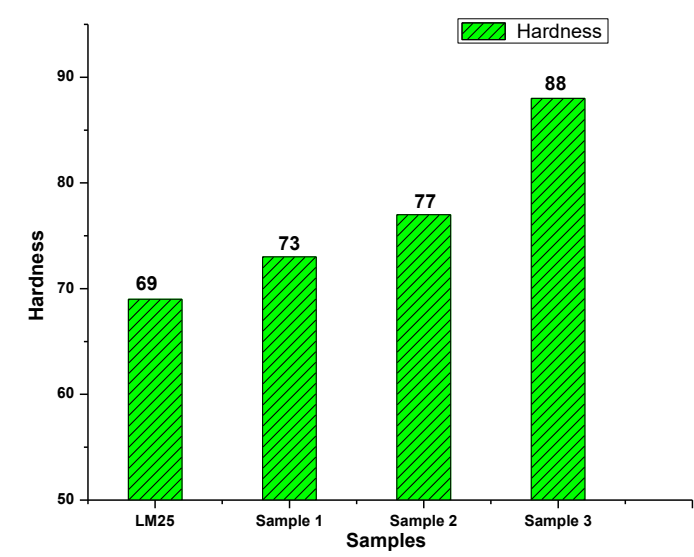

Fig.5. Hardness values of composites

\subsection{Tensile strength}

Tensile strength samples results are shown in Fig.6. The stresses of the first, second and third samples are $134 \mathrm{MPa}, 147 \mathrm{MPa}$ and $156 \mathrm{MPa}$ respectively. Compare then base alloy, sample 3 tensile strength has increased $22 \%$. Elongation percentages are shown in Table 4. 
Table 4. Elongation Values of Composites

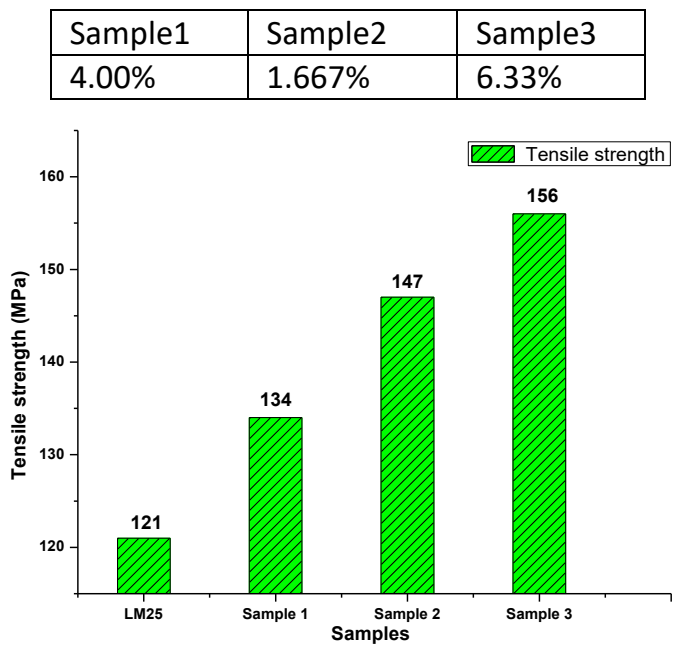

Fig.6. Tensile strength of composites

\subsection{Microstructure}

Sample 1 (LM25/10SiC/0mica): The particles are not evenly distributed and seem to be scattered. The microstructure shows fine inter-dendritic pattern of Al-Si eutectic particles in Al solution. The composite particles occupied the grain boundary cavity voids. This can be adhered from Fig.7.

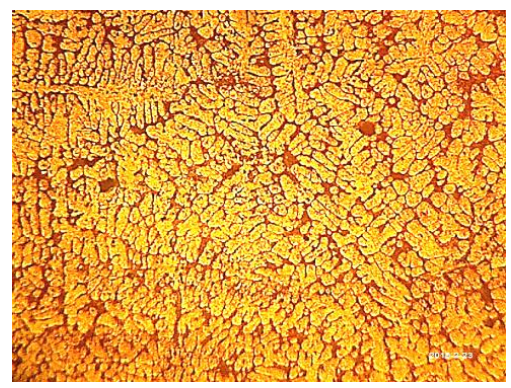

Fig.7. Microstructure of sample 1

Sample 2 (LM25/10SiC/3mica): The particles are not evenly distributed and seem to be scattered. The microstructure shows fine inter-dendritic pattern of Al-Si eutectic particles in Al solution. The composite particles are less in percentage and the distribution is uniform in the matrix. This can be adhered from Fig.8.

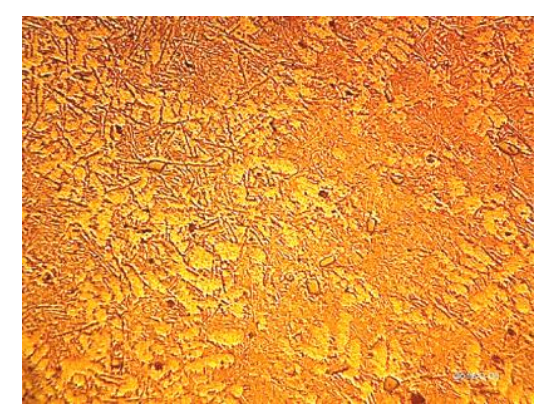

Fig.8. Microstructure of sample 2
Sample 3 (LM25/10SiC/5mica): The particles are not evenly distributed and seem to be scattered. The higher percentage of composite particles has led to higher distribution in the metal matrix. The composite particles occupied the grain boundary cavity voids. This can be adhered from Fig.9.

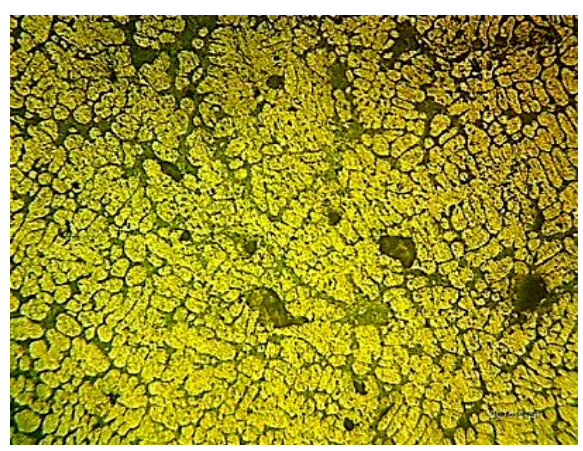

Fig.9. Microstructure of sample 3

\subsection{SEM}

The SEM micrographs of LM25/10SiC/5mica composites are shown in Fig.10 and 11 for the third sample LM25/10SiC/5mica.

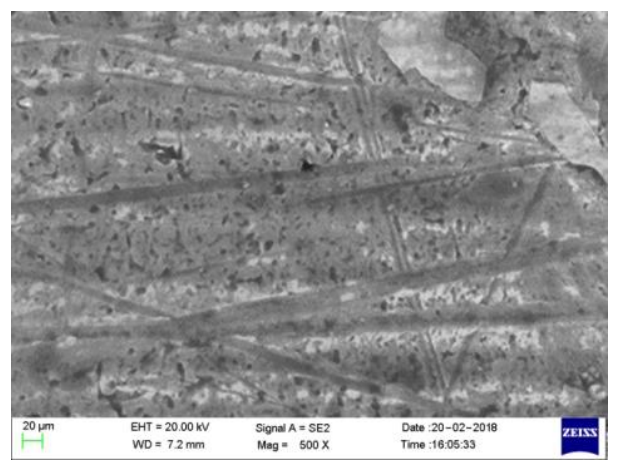

Fig.10. Distribution of SiC

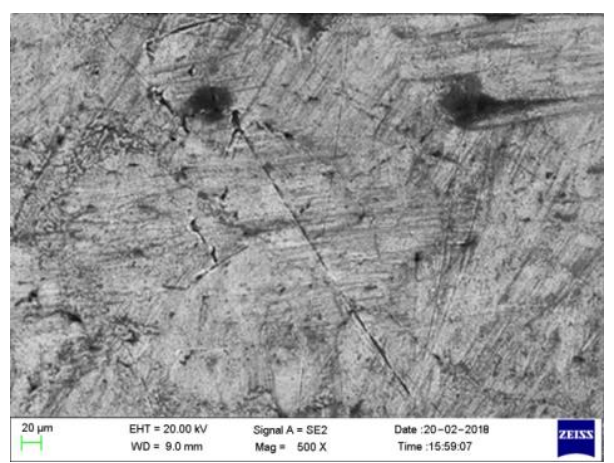

Fig.11. Distribution of mica

SEM and EDAX report confirms the presence of carbon $(6.84 \%$ by weight), oxygen $(1.04 \%$ by weight), aluminium ( $90.64 \%$ by weight) and silicon ( $1.49 \%$ by weight). Fig.12 shows the presence of the elements by weight. 


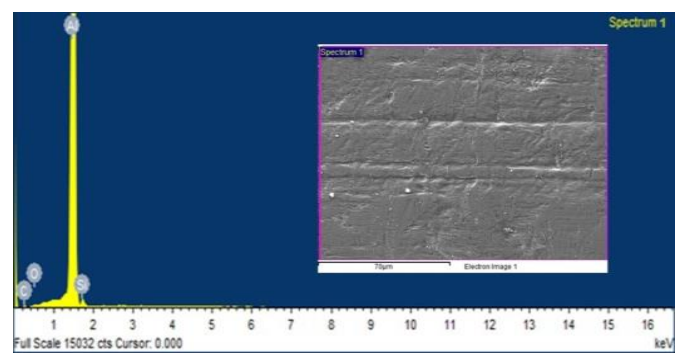

Fig.12. EDS analysis of sample 3

\subsection{Wear loss}

Wear loss test was carried for the three samples with base material. Coefficient of friction (COF) for each samples mentioned in Table 5. The initial and final weights of the three samples are shown in Table 4.

Table 5. Wear loss and COF

\begin{tabular}{|c|c|c|c|}
\hline $\begin{array}{c}\text { Sample } \\
\text { ID }\end{array}$ & $\begin{array}{c}\text { Initial weight } \\
\text { in "g" }\end{array}$ & $\begin{array}{c}\text { Final weight } \\
\text { in "g" }\end{array}$ & COF \\
\hline 1 & 4.15 & 4.05 & 0.875 \\
\hline 2 & 4.051 & 4.048 & 0.684 \\
\hline 3 & 3.917 & 3.915 & 0.512 \\
\hline
\end{tabular}

Fig.13 shown from wear test that with addition of composition of mica the composite becomes more resistive to wear loss.

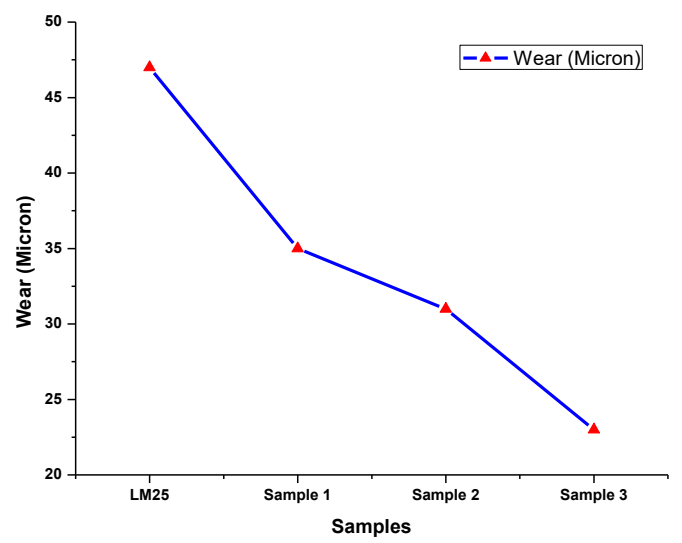

Fig.13. Wear micron

\section{CONCLUSIONS}

LM25 alloy reinforced SiC with different wt\% of mica were successfully prepared by squeeze casting technique. The samples were characterized and drawn the following conclusions are:

- Squeeze casting technique was suitable to fabricate the LM25 HMMC;

- Increasing the wt\% of mica, composite shows higher density;
- Sample 3 (LM25/10SiC/5mica) shows maximum hardness and tensile strength. It has increased $22 \%$ compare then base metal;

- Microstructure observed that sample 3 shown good bonding and less voids compare to other samples;

- SEM exposed less agglomeration with uniform distribution and EDS shown presence of reinforcement in sample 3;

- COF decreased with increasing mica wt\%;

- It was found that with increase in amount or composition of mica in the composite, a more wear loss resistive material can be obtained.

\section{REFERENCES}

[1] B. Stojanovic, M. Bukvic, I. Epler, Application of Aluminum and Aluminum Alloys in Engineering. Applied Engineering Letters, 3(2), 2018: 52-62.

https://doi.org/10.18485/aeletters.2018.3.2.2

[2] L. Natrayan, M. Senthil Kumar, Study on Squeeze Casting of Aluminum Matrix Composites - A Review. In: Antony K., Davim J. (eds) Advanced Manufacturing and Materials Science. Lecture Notes on Multidisciplinary Industrial Engineering. Springer, Cham, 2018.

https://doi.org/10.1007/978-3-319-76276-0 8

[3] B. Stojanovic, J. Glisovic, Automotive Engine Materials, in: Saleem Hashmi (Ed), Reference Module in Materials Science and Materials Engineering, Oxford: Elsevier, 2016: pp. 1-9.

[4] M. Senthil Kumar, L Natrayan, R.D. Hemanth, K. Annamalai, E. Karthick, Experimental Investigations on Mechanical and Microstructural Properties of $\mathrm{Al}_{2} \mathrm{O}_{3} / \mathrm{SiC}$ Reinforced Hybrid Metal Matrix Composite. IOP Conference Series: Materials Science and Engineering, 402(1), 2018: 012123. https://doi.org/10.1088/1757-899X/402/1/012123

[5] M. Rosso, Ceramic and Metal Matrix Composites: Routes and Properties. Journal of materials processing technology, 175(1-3), 2006 : 364-375.

https://doi.org/10.1016/j.jmatprotec.2005.04.038

[6] L. Natrayan, M. Senthil Kumar, K. Palanikumar, Optimization of Squeeze Cast Process Parameters on Mechanical Properties of Al2O3/SiC Reinforced Hybrid Metal Matrix Composites Using Taguchi Technique. Materials Research Express, 5(6), 2018: 066516. 
[7] S.R. Patil, B.S. Motgi, A Study on Mechanical Properties of Fly Ash and Alumina Reinforced Aluminium Alloy (LM25) Composites. Journal of Mechanical and Civil Engineering, 7(6), 2013: 41-46.

[8] B. Stojanović, L. Ivanović, Application of Aluminium Hybrid Composites in Automotive Industry. Tehnički vjesnik, 22 (1), 2015:247251.

https://doi.org/10.17559/TV-20130905094303

[9] M. Senthil Kumar, R. V. Mangalaraja, R. S. Kumar, L. Natrayan, Processing and Characterization of $\mathrm{AA2024} / \mathrm{Al}_{2} \mathrm{O}_{3} / \mathrm{SiC}$ Reinforces Hybrid Composites Using Squeeze Casting Technique. Iran. J. Mater. Sci. Eng., 16 (2), 2019: 55-67.

[10] S. Ke, C. Chen, N. Fu, H, Zhou, M. Ye, P. Lin, W. Yuan, $X$. Zeng, L. Chen, H. Huang, Transparent indium tin oxide electrodes on muscovite mica for high-temperature-processed flexible optoelectronic devices. ACS Applied Materials and Interfaces. 8(42), 2016: 28406-28411. https://doi.org/10.1021/acsami.6b09166

[11] B. Stojanovic, M. Babic, S. Mitrovic, A. Vencl, N. Miloradovic, M. Pantic, Tribological Characteristics of Aluminium Hybrid Composites Reinforced with Silicon Carbide and Graphite. Journal of the Balkan Tribological Association, 19(1), 2013:83-96.
[12] Yashpal, Sumankant, C.S. Jawalkar, A.S. Verma, N.M. Suri, Fabrication of Aluminium Metal Matrix Composites with Particulate Reinforcement: A Review. Materials Today: Proceedings, 4(2), 2017: 2927-2936. https://doi.org/10.1016/j.matpr.2017.02.174

[13] M. Babić, B. Stojanović, S. Mitrović, I. Bobić, N. Miloradović, M. Pantić, D. Džunić, Wear Properties of A356/10SiC/1Gr Hybrid Composites in Lubricated Sliding Conditions, Tribology in Industry, 35(2), 2013: 148-154.

[14] L.Natrayan, M. Singh, M. Senthil Kumar, An experimental investigation on mechanical behaviour of SiCp reinforced Al 6061 MMC using squeeze casting process. Inter. J. Mech. Prod. Engi. Res. Develop., 7(6), 2017:663-668. https://doi.org/10.24247/ijmperddec201774

[15] S. Yogeshwaran, R. Prabhu, L. Natrayan. Mechanical Properties of Leaf Ashes Reinforced Aluminum Alloy Metal Matrix Composites, International Journal of Applied Engineering Research, 10(13), 2015: 1104811052.

[16] R.D. Hemanth, M. Senthil Kumar, A. Gopinath, L. Natrayan, Evaluation of Mechanical Properties of E-Glass and Coconut Fiber Reinforced with Polyester and Epoxy Resin Matrices, International Journal of Mechanical and Production Engineering Research and Development, 7(5), 2017: 13-20. 